\title{
Play Like A Woman! An Overview of Gender from The Perspective of Physical Education Football Players' Female Students
}

\author{
Naci Kalkan, PhD \\ Manisa Celal Bayar University, Turkey \\ Sabiha Gizem Engin \\ Anadolu University, Social Sciences Institute, Turkey
}

Doi:10.19044/ejes.v7no4a8 URL:http://dx.doi.org/10.19044/ejes.v7no4a8

\begin{abstract}
In this study, by determining the thoughts of women footballers about their experiences in football fields; aims to reveal female footballers and social reactions, and to take steps towards solving the problems. A semi-structured interview form created by the researchers consisting of a total of five questions was used in the interviews with the female football players who are studying at the Physical Education and Sports Department. In the process of creating the questions in the interview forms, a literature review was conducted, and expressions describing the existing situation were included. As a result of the interviews, the concept of "hegemonic masculinity" formed our main theme. There are three sub-themes under the main theme of hegemonic masculinity, which are "negative discrimination, discourses, and expectation". These main and sub-themes that are determined contain various codes. In the light of the data obtained, it could be noted that female football players have not yet earned their rights adequately compared to male football players in 2020 , and they have not, however, overcome the barriers of the male-dominated football world in the field and their social lives.
\end{abstract}

Keywords: Gender, Football, University, Woman.

\section{Introduction}

The violence which defines the extremes, roughness, vulgar behaviors is one of the major problems we face in social life. Violence represents the extent of action, a force. This concept is considered in sports and football as the act of changing the outcome by resorting to force, instead of persuading or finding common ground between opposing sides. Being one of the most significant figures of the industrialized world and the fact that the competition attracts the people football has acquired a worldwide network both with the 
economy it creates. The social and economic network created by the world of football ensures that the intensity of competition is not lost. Having ties in all kinds of social environments stretching from media, social media, press, audience, groups of friends to the streets may cause the rise of acts of violence and aggression due to the continuous fostering of the intense emotions and competition dynamics contained internally. The level of football has reached with the help of the press, and the media has provided a wide range of influence from international relations to economic impact. It has not been possible for individuals to be indifferent to football matches at the points where these levels have reached. The factors causing individuals to attend football matches as the audience has caused it to become one of the biggest stress release forms (Türkmen, 1998). The process of stress release may cause extreme actions due to a wide variety of causes such as failure to manage the feeling of overexcitement present like football, to it becoming an arena for opposing ideological or religious groups. Although it is evident that this process of stress release has a direct impact on violence and aggression in football, it may negatively affect all stakeholders in this network football has created. Therefore, the organizations working towards preventing violence in football, and the individuals who exert violence have different perceptions. The growing tension between organizations and individuals has contributed to the implementation of various measures. Still, it has not been possible to prevent incidents resulting in the injury or death of many individuals. Thus, it could be noted that violent acts in football have a hidden depth. In-depth analyzing the factors that cause acts of violence and aggression in football can be beneficial not only for decreasing loss of life or property but also for identifying the cultural causes (Dunning et al., 1986). The most common examples of violence in football are the discourse that contains swear words and insults. We see the fact that these expressions generally are stated in a sexist manner is publicly known and academically presented. When we get to the bottom of the historical and sociological bases of this sexist discourse, reasons such as women's role being reduced to doing chores and raising children until the 19th century, women newly starting to take part in labor in the world rapidly developing with the Industrial Revolution caused the struggle of women to achieve the right of equality on a social level to be a challenging and time-consuming period. This situation caused discrimination against and denial of the role of women in sports as well as it had in the workplace (Kidd, 2013). The perspective that prevented women from participating in sports activities fed on the mindset that women lacked physical skills and women's fundamental social duties did not allow such activities. It became inevitable for men to be at the center of sports culturally and numerically when sports activities were defined by high levels of performance, superior physical attributes, talent, success, ambition, and 
records (Koca and Bulgu, 2005). Sexist discourse is discussed as the language based on inequality which brings with itself the perspective that the existing patriarchal social structure is absolute. It naturalizes, legitimizes, reinforces, and regenerates this situation (Akbaş, 2012). The fact that sexist language is used as an insult and is focused on womanhood makes it necessary for our country and the world to develop actions towards solutions. It is observed in the course of institutionalization of football that establishing an equivalent to the notion of promoting the equality of language, religion, race, gender that sports suggest, has required highly significant effort in the world of football which has established patriarchal networks. We acknowledge the establishment of several professional leagues after the overcoming of the historical obstacles keeping women from playing football. Nevertheless, the economic gap between male and female football players persists. Many problems of women and the football world are addressed both in academia and on the world media. Being an ongoing behavior in male football, we observe the use of sexist language in female football as well. Starting with this perspective, academically portraying this situation by identifying the experiences and opinions of professional female football players on football fields will be sufficient in demonstrating female footballers and social reactions, and in creating steps to be taken towards solving the problems experienced.

From the results of the study, it is aimed to draw attention to the problems caused by the sexist approach in the world of football, to discuss the solutions and to contribute to the literature by identifying the issues of women's football.

\section{Method}

The interviews enable direct quotations about individual experience, opinion, feeling, and knowledge (Patton, 2014).

In this respect, the importance of interviews emerges in terms of the subject, purpose, and context of our study, since the subject is sensitive and to reach conclusions of quality and to be able to extract in-depth and detailed information (Y1ldırım and Şimşek, 2003). With the idea that the in-depth and detailed information to be gathered from interviews to be conducted with the licensed female football players making up the sample study group would directly impact the goals of the study. The study was chosen to be performed with an in-depth interview technique of qualitative research methods.

A semi-structured interview form created by the researchers consisting of a total of five questions was used in the interviews with the female eight football players who are studying at Manisa Celal Bayar University Physical Education and Sports Department. In the process of creating the questions in the interview forms, a literature review was conducted, and expressions 
describing the existing situation were included. Submitted for the expert review, the form was revised according to feedbacks and was made ready for application by the researchers. The questions in the semi-structured form created concerning the determined goals are as in Table 1.

Table 1. Semi-Structured Interview Form Questions

1 1. Do you think there is positive or negative discrimination against women in football?

22 Do you think there is a sexist approach in the language used towards women in the football field? Are there any incidents you have experienced or that caught your attention, could you share it?

33 . Do you think women and men are equal in football?

44 . How would you interpret and illustrate the behavior towards women in the football field?

5 5. Have you been subject to any aggression during your football career?

The participants of the study are female football players licensed under the Turkish Football Federation. Within the scope of the study, an e-mail was sent to the participants containing information on the purpose of the study, and interviews were planned with eight players who volunteered to participate. The details of the participating players are as in Table 2.

Table 2. Details of the Participants

\begin{tabular}{lllll}
\hline Participant & Age & $\begin{array}{l}\text { Monthly } \\
\text { (TRY) }\end{array}$ & Income & License(Year) \\
Participant-1 & 21 & 2650 & 7 \\
Participant-2 & 22 & 2600 & 7 \\
Participant-3 & 21 & 3200 & 7 \\
Participant-4 & 23 & 3000 & 11 \\
Participant-5 & 21 & 2800 & 7 \\
Participant-6 & 21 & 2800 & 12 \\
Participant-7 & 23 & 2850 & 9 \\
Participant-8 & 22 & 3500 & 10 \\
\hline
\end{tabular}

The researchers planned the interviews according to the date and time mutually agreed with the participants and conducted the interviews at a period suitable for the interviewer. The participants were informed about the study by the researchers, and a consent form that guaranteed the confidentiality of the information and the data only to be used for scientific purposes was mutually signed before the interview. The interviews were recorded with the 
participants' agreement. The information about the interviews is presented in Table 3.

Table 3. Details of the Interviews

\begin{tabular}{ll} 
Participant & Interview (min.) \\
Participant-1 & 49,36 \\
Participant-2 & 57,55 \\
Participant-3 & 67,11 \\
Participant-4 & 34,28 \\
Participant-5 & 35,05 \\
Participant-6 & 46,31 \\
Participant-7 & 38,22 \\
Participant-8 & 47,32 \\
\hline
\end{tabular}

The recorded interviews were deciphered and converted into text. The interviews converted into texts have been coded following the content analysis by three researchers who hold doctorate degrees and were made into themes and sampled. Since there is no conceptual structure to guide the analysis of the collected data, this structure has emerged as a result of subjecting the collected data to inductive analysis. This is the main reason why content analysis was chosen for this study. The researchers interpreted the texts separately by looking at the number of concepts in the text, their meaning, the relationship between the concepts, and the emphasis on the ideas and expressions, and then evaluated them comparatively. As a result of the evaluations, a conclusion on the texts in hand has been reached, and the analysis has been completed.

\section{Results}

Female football players and gender themes and codes were included in this section, including the findings obtained from the analysis of the information gathered from the interviews. The opinions of the participants were also stated as "quotations" in the findings section, and all the findings were obtained as a result of the personal views of the participants. While sharing the opinions of the participants, the identity of the participant was not used, only the number given to the participant was used.

\section{Themes, Sub-Themes, and Codes}

As a result of the interviews, the concept of "hegemonic masculinity" formed our main theme. There are three sub-themes under the main theme of hegemonic masculinity, which are "negative discrimination, discourses, and expectation". These main and sub-themes that are determined contain various codes. Sub-themes and codes in regard are given in Figure 1: 
Figure 1. Main Theme, Sub-Themes, Code, and Sub-Codes

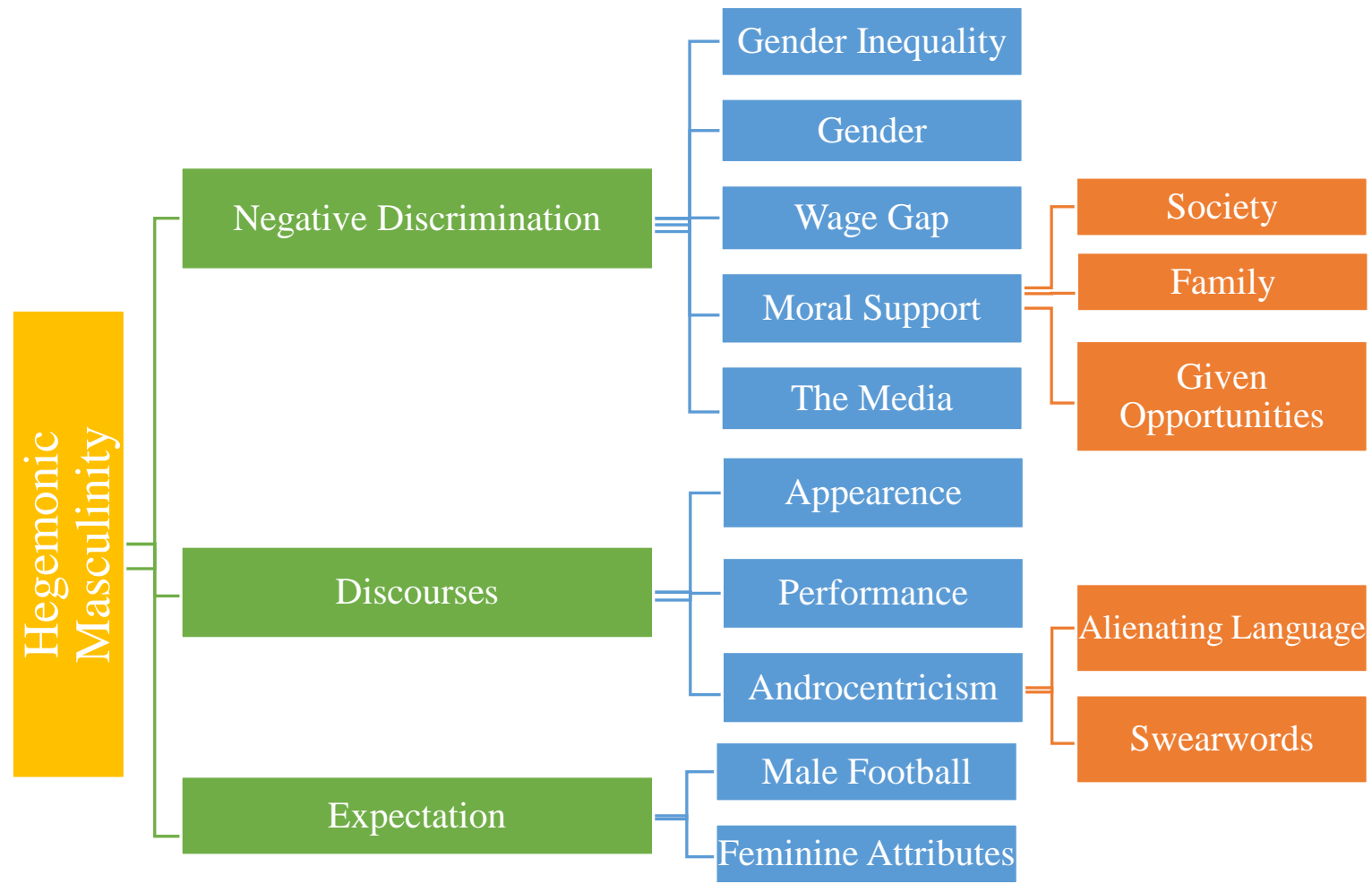

The details regarding the codes under the sub-theme of "negative discrimination" titled "gender inequality, gender, wage inequality, moral support" and "media" are as follows;

\section{Gender Inequality}

Noting that they are always seen as inferior to the opposite sex Female football players stated that this is not true and they express their opinions on this situation as follows;

Participant-1: "I don't think we are equal in society. Men seem superior in every aspect, but I don't think we are different, I think we are equal."

Participant-3: "Of course we have physical and anatomical differences, but our opponents are same-sex players. Therefore I don't think anything is setting them or us superior to each other. Yet I think we see the 
value put on male football is a lot bigger than that of female football in our country."

Participant-5: "When every woman is inherently different than every other woman, and every man is inherently different than every other man, I sincerely think it doesn't make sense to compare women to men. But these differences do not justify sexism either."

English (1978) supports female football players by stating that football, being a masculine sports branch, contains a strong sense of masculinity and this situation causes the alienation of any gender and behavior other than the masculine. Women, as they become the alienated gender, see themselves as insignificant in football. This insignificance then shows the inequality between the two genders.

A study conducted by Davis et al's (2019) on female football players in the U.K. shows results supporting our research concerning this gender inequality. In the research conducted, the idea that female football players are physically disadvantaged against male football players, and the opinion that it would harm the women if they compete together was discussed. While the necessity of gender integration in football is addressed, it is stated that the repressive mindset of the British Football Federation is far from equality and justice (Davis et al., 2019).

Besides, the research conducted by Simon et al. (2015) reveals that women struggle for equality mostly in popular fields of sports where the physiological superiority of men is evident, and this supports our study regarding football being one of the most popular sports.

\section{Gender}

Female football players stated that playing ball was never seen as a profession fit for them, that they struggled to exist in this field and tried to destroy the perception of football as being a masculine job. The opinions of the participants regarding this situation are as follows;

Participant-2: "Football is perceived more as a job for men in Turkey. I mean, male football players get more support than women."

Participant-5: "I think there's negative discrimination towards women. Because since the beginning, the idea of a women's job is to stay at home and do chores... It is not surprising in an environment where this is the general mindset."

Participant-6: "We live in a society where the general mindset is that football is not for women."

Bryson (1987) and Connell and Messerschmidt (2005) define gender by stating that there are different roles in societies and that these roles are 
assigned to the sexes differently. One of these mentioned assignments is, of course, created with the perception that football is a masculine game.

In his study, Williams (2013) stated that despite the rise of football, women have a minimal presence in this field, especially emphasizing that female coaches do not get hired, and obtained results similar to our study with the emphasis on gender.

\section{Wage Gap}

Female football players in our study receive an average of less than 1000 TRY per month in from their licensed football profession, and this is well below the earnings of their male colleagues with the same status. The opinions of the participants regarding this situation are as follows;

Participant-1: "Women are supported less economically similar to other aspects."

Participant-6: "I don't think it is equal. We are not equal to men either economically or morally."

Participant-8: "There is a colossal difference between the men's national team and women's national team when we look at it in terms of both the significance they acquire and the salary they get. Or the youth setup of Galatasaray and the youth setup of the women's team don't get the same appreciation."

Women struggle with wage inequality in sports as in many jobs. Women often play football voluntarily or continue their profession in sports with meagre wages. As a result of research, Sporting Intelligence (2018) stated that even in countries where women's football is relatively developed, among the elite players' women earn one per cent of the total of their male colleagues. Besides, the average first-team salary in the Premier League rose to $£ 2.64$ million in 2017, while the equivalent, the average salary in the Women's Super League, was $£ 26,752$. This situation itself is an explanation of women's wages in our country.

Nevertheless, there is also protest from American and Danish female football players against wage inequality. They demand equal pay with their male counterparts at the same professional status and are supported by their male counterparts. Danish and Norwegian male football players have expressed their opinion that women players deserve equal payment and offered to pay back from their earnings for equal pay (Wrack, 2017; Stump, 2016).

\section{Moral Support}

In addition to financial support for women's football, participants expect to be supported by society and their families. They also state that they 
are exhausted since their clubs do not provide equal conditions compared to men. Participants' opinions on this issue are as follows;

Participant-3: "We don't make the same money as men. We don't have the same opportunities. We don't get nearly as much attention as the male players in media or social life. Not just a player, anybody would choose to sleep on the streets than our facility. They have 5-course meals served in the men's facility of the same club." society."

Participant:4: "Football is clearly under male dominance in our

Participant-7: "Our facilities are inadequate. The fields we play on are like potato fields and our practice hours are arranged according to the men's practice hours. They serve different meals for teams of other sports branches than ours at the facility. Our rooms are for 3-4 people while the others are for 1-2 people."

The study carried out by Wangari et al. (2017) in Kenya includes findings that support our study, revealing that women are not provided with equal opportunities with men, their access is minimal, and men are always prioritized.

In the literature review, many studies are revealing that many studies have been conducted to support women's football and that the society and official institutions support women's football, female football players, female referees, and coaches (Clarkson and Cox, 2019; Pfister and Pope, 2018; Lewis et al., 2018; Blair and Hess, 2017; Pope, 2016; Dunn, 2016). However, women in our study expressed that they could not feel this support either from society or their families. Therefore, there are differences in opinion compared to the literature.

\section{Media}

Participants discussed that representation of women on the media is not enough, and state their opinions about the relation between women's football and media;

Participant-6: "We have sports news in media every day whether it is the newspaper or T.V. news, but none of these includes women's football."

The research conducted by Cooky et al. (2015) reveals that only $3.2 \%$ of the sports news in the American media is dedicated to women's sports, and thus support the findings of our research.

In their study, Dunn and Pivot (2016) have stated that women are referred to and be newsworthy by their feminine qualities not only in football, but in almost all sports branches, and emphasized that rough branches such as football cannot be used as a media material. Therefore, this makes it harder 
for them to appear on the media. The reason behind the media code, which is also among our findings is in parallel with this study.

Besides, in the research conducted by Dunn in 2018 concerning the media coverage of team sports and especially team sports like football associated with men, it is emphasized that female athletes cannot achieve equal representation if they contain non-threatening behaviors.

Details on the codes titled "appearance, performance, male dominance" under the "Discourses" sub-theme are as follows;

\section{Appearance}

Participants stated that they received comments about their physical appearances such as they looked like men and deemed suitable for specific sexual orientations. They say that these discourses are based on the masculinity of football. Participants' opinions on this situation are as follows;

Participant-1: "I have short hair. I go to games. Say I went to an away game. Because I have short hair, I hear from the tribune things like 'there's a man on the field'. I think the reason is that football is seen as a men's sport."

Participant-6: "Especially in our country there's a saying associated with referees, excuse my language, 'bastard referee'. We face this type of insult in our field because of our physical structure, as 'tomboy' and 'lesbian'. We hear a lot of implications of homosexuality,"

In their study, Gubby and Wellard (2016) highlighted that the women playing korfball described themselves as "Tomboys" and were referred by such definitions in the society due to their physical properties. Therefore, they revealed data supporting our study.

\section{Performance}

Participants stated that women are compared to men, and this is something wrong, and they expressed their sensitivities on the subject that women should be compared to other women and commented on this basis;

Participant-2: "In football, women are expected to compete as rough as men. Meanwhile, people are watching females playing football; they expect women to show rough competition as men. They are not aware that a sport, I mean any sport not only football, can be played intersexually."

Participant-7: "For example, in some games, our referees act as if they are our trainers, showing how to take a throw-in sort of behavior, and this makes no sense and isn't fair at all. There's a strict notion that women can't play football."

The research conducted by Elbert et al. (2010) clarifies the basis of the attachment by stating that the violence embodied in male football creates an 
appetizing motivation in people. As revealed by our study, this motivation can be the reason why women's football is viewed as naïve and compared to performances of male football players.

\section{Male Dominance}

Participants complained about male-dominant language and sexist discourses, and they expressed the discomfort they have about the language which constantly marginalized women as well as the swear words they hear;

Participant-2: "Stating like 'this is not a football-playing', 'is this how you play ball', 'don't escape from competition', 'break her leg' are things mostly said in male football and are very annoying."

Participant-5: "I think the female referee conducting the game saying 'don't cry like a woman' to the players summarizes everything. The fact that men are glorified so much, and the women have devalued shows that we are a patriarchal society."

Participant-7:" There shouldn't be any petty swearing behind one's back. The context of the swears is generally sexist, but generally, in our country, the swearwords are sexist anyway."

Participant-8: "Phrases like 'man to man competition', 'don't play like a girl', 'technical man (used for coach)' are all sexist phrases, and because being a man is associated with masculinity and the male, the notion that football is for men is established. These phrases exist in branches other than football. We don't want these sexist discourses."

In their research, Connell and Messerschmidt (2005) have found that male dominance in Latin America's football world in terms of both practice and discourse will continue for long years unless the society changes. Arguing that this male dominance will shape not only gender identities and roles, but also the future practices, and revealing the male dominance within football, they emphasize on common grounds with our study.

Details on the codes titled "male football and feminine qualities" under the "expectations" sub-theme are as follows;

\section{Men's Football}

Female football players have stated that they are constantly compared to men and expected to display man-like behaviors and performances. They mentioned that the performance-related differences between women and men as accepted in other branches must also be accepted in football. Opinions on this subject are as follows;

Participant-1: "Men and women are different physically and anatomically, but in the field offootball, there is something else. For example, when we are on the field practicing, or at a game competing for one on one 
and we face a negative outcome, our coaches ask us to use more force, or when I whip across. The ball falls short they tell me to hit the ball harder, what I mean to say is they expect us to play like they see men play. But we are different, and we can't pull the same game."

Participant-2: "The audience expects the moves of men when they are watching women play the game."

Participant-8: "I think there is a sexist approach behaviour-wise. We are asked to play like men or talk like men, or even swear as they do. For example, sometimes people ask me if I swear on the field. They expect us to react like men, but they are missing the point that we are women and we play like women."

\section{Feminine Features}

Female football players complain about a structure that expects performance like a man but does not want feminine features to be lost, and expressed the comments they received in terms of the changes in their appearance;

Participant-2: "I even heard some implications from my father after starting to play football like 'you started walking like a boy', 'you are acting like a boy'. Yes, football is a little rough as a game, but it is not a field people should choose according to their gender."

Participant-6: "We encounter a lot of implications of homosexuality because of our changing physical stature. I don't think this is offensive, but people are implying them as insults. Football became such a men's sports and playing football as a w; we, we automatically face sexist insults."

Gubby and Wellard (2016) state that women are forced to be attractive all the time and to abstain from losing their femininity. Gubby and Wellard associate the fact that women are forced to wear skirts and be well-groomed in Korfball with expectations of the audience, suggest that this does not pertain to only one branch and the expectations are similar in almost every sports branch, and thus support the concern about losing the feminine qualities as we have found in our study.

\section{Conclusion}

In the light of the data obtained, it could be noted that female football players have not yet earned their rights adequately compared to male football players in 2020, and they have not, however, overcome the barriers of the male-dominated football world in the field and their social lives. It should be stated that the stakeholders do not experience gender equality even in an egalitarian environment such as sports, and the social studies conducted in this 
area are not able to adequately fulfill the demands of women in the football world.

\section{References:}

1. Akbaş, E. (2012). Türkiye'de sosyal medyada futbol taraftarlarının erkeklik söylemleri (Doctoral dissertation, istanbul Bilgi Üniversitesi).

2. Blair, D., \& Hess, R. (2017). Women, War, and Football. In Australian Rules Football During the First World War (pp. 53-68). Palgrave Macmillan, Cham.,

3. Bryson, L. (1987). Sport and the maintenance of masculine hegemony. In Women's Studies International Forum (Vol. 10, No. 4, pp. 349-360). Pergamon Press.

4. Pope, S. (2016). Female fans of men's football. Hughson, J., Maguire, J., Moore, K. \& Spaaij, R. Routledge (Eds) Routledge Handbook of Football Studies. Abingdon. Routledge.

5. Clarkson, B. G., Cox, E., \& Thelwell, R. C. (2019). Negotiating gender in the English football workplace: Composite vignettes of women head coaches' experiences. Women in Sport and Physical Activity Journal, 27(2), 73-84.

6. Connell, R. W., \& Messerschmidt, J. W. (2005). Hegemonic masculinity: Rethinking the concept. Gender \& Society, 19(6), 829859.

7. Cooky, C. (2018). Sociology of gender and sport. In Handbook of the sociology of gender (pp. 459-467). Springer, Cham.

8. Edwards, L., Davis, P., \& Forbes, A. (2015). Challenging sex segregation: A philosophical evaluation of the football association's rules on mixed football. Sport, ethics and philosophy, 9(4), 389-400.

9. Dunn, C. (2016). Football and the women's World Cup: organisation, media and fandom. Springer.

10. Dunn, C. (2018). Media coverage of women's sport: Personal reflections. In The Palgrave handbook of feminism and sport, leisure and physical education (pp. 841-853). Palgrave Macmillan, London.

11. Dunning, E., Murphy, P., \& Williams, J. (1986). Spectator violence at football matches: Towards a sociological explanation. British Journal of Sociology, 221-244.

12. Elbert, T., Weierstall, R., \& Schauer, M. (2010). Fascination violence: On the mind and brain of manhunters. European archives of psychiatry and clinical neuroscience, 260(2), 100-105.

13. English, J. (1978). Sex equality in sports. Philosophy \& Public Affairs, 269-277.

14. Gubby, L., \& Wellard, I. (2016). Sporting equality and gender neutrality in korfball. Sport in Society, 19(8-9), 1171-1185. 
15. Intelligence, S. (2017). Global sports salaries survey.

16. Kidd, B. (2013). Sports and masculinity. Sport in society, 16 (4), 553564.

17. Koca, C., \& Bulgu, N. (2005). SPOR VE TOPLUMSAL CINSIYYET: GENEL BİR BAKIŞ.

18. Lewis, C. J., Roberts, S. J., \& Andrews, H. (2018). 'Why am I putting myself through this?' Women football coaches' experiences of the Football Association's coach education process. Sport, education and society, 23(1), 28-39.

19. Patton, M. Q. (2014). Qualitative research \& evaluation methods: Integrating theory and practice. Sage publications.

20. Pfister, G., \& Pope, S. (Eds.). (2018). Female Football Players and Fans: Intruding into a man's world. Springer.

21. Simon, R. L. (2018). Fair play: The ethics of sport. Routledge..

22. Stump, S. 2016. "U.S. Women's Soccer Stars Filing Equal Pay Complaint."

23. Türkmen HN. Çă̆ımızda Bacasız Sanayi: Futbol. İstanbul: TFF Yayınlar1; 1998.

24. Wangari, G., Wango, D., \& Kimani, P. (2017). Challenges Faced By Women Football Players Who Participate In Football Leagues. Journal Of Developing Country Studies, 2 (1), 13-35.

25. Williams, J. (2013). A game for rough girls?: a history of women's football in Britain. Routledge.

26. Wrack, S. (2017). Norway's historic pay deal for women's team shows it can be done'. The Guardian, 17.

27. Yıldırım, A., \& Şimşek, H. (2003). Sosyal bilimlerde nitel araştırma yöntemleri. Seçkin yayıncılık 